\title{
PENATAAN LINGKUNGAN DENGAN PENANAMAN POHON UNTUK MENCEGAH TERJADINYA LONGSOR DI DESA URUG, SUKAJAYA, BOGOR
}

\author{
Patria Adhistian'), ${ }^{1)}$ Mairizal ${ }^{2)}$, Tedi Dahniar ${ }^{3)}$ \\ ${ }^{1,2,3}$ Program Studi Teknik Industri, Fakultas Teknik, Universitas Pamulang
}

\begin{abstract}
Abstrak
Indonesia dalam periode musim penghujan setiap tahunnya, seringkali dilanda bencana longsor. Ada beberapa kejadian yang menimpa Provinsi Jawa Barat dan khususnya di Kabupaten Bogor. Salah satu lokasinya berada di Desa Urug Kecamatan Sukajaya Kabupaten Bogor. Adapun penyebab utama bencana longsor tersebut adalah dikarenakan curah hujan yang tinggi, akan tetapi tanah tidak sanggup menampung air hujan tersebut. Hasil identifikasi dengan mengambil informasi dari beberapa kalangan masyarakat disekitar lokasi maupun dari korban bencana longsor sendiri, dapat diambil kesimpulan bahwa bencana longsor memang terjadi diakibatlan oleh penebangan hutan secara liar. Sementara ini, solusi penggulangannya sedang dibuatkan Rumah Khusus (Rusus) dari Pemerintah untuk korban bencana longsor tersebut. Lokasinya bertepatan di depan Kantor Desa Urug seluas \pm 8 hektar. Untuk menunjang program Pemerintah dalam mengantisipasi bencana longsosr selanjutnya, perlu dilakukan sosialisasi kepada masyarakat agar peduli lingkungan dengan salah satu cara yaitu penanaman pohon kembali (reboisasi). Didalam program ini akan disampaikan pemahaman akan pentingnya menjaga lingkungan dari berbagai aspek kehidupan dan salah satunya dengan penanaman pohon-pohon disekitar rumah dan lereng pemukiman.
\end{abstract}

Kata Kunci : lingkungan, penebangan liar, tanah longsor, penanaman pohon.

\begin{abstract}
Indonesia, in the rainy season every year, is often hit by landslides. There are several incidents that have happened to West Java Province and especially in Bogor Regency. One of the locations is in Urug Village, Sukajaya District, Bogor Regency. The main cause of the landslide disaster is due to high rainfall, but the soil cannot accommodate the rainwater. The results of the identification by taking information from several communities around the location and from landslide victims themselves, it can be concluded that landslides do occur as a result of illegal logging. In the meantime, the solution for its removal is being made a Special House (Rusus) from the Government for victims of the landslide disaster. The location coincides in front of the Urug Village Office covering an area of \pm 8 hectares. To support the Government's program in anticipating the next landslide disaster, it is necessary to conduct socialization to the community to care for the environment in one way, namely reforestation. This program will convey an understanding of the importance of protecting the environment from various aspects of life and one of them is by planting trees around houses and residential slopes.
\end{abstract}

Keywords: environment, illegal logging, landslides, tree planting 


\section{PENDAHULUAN}

\subsection{Latar Belakang}

Lingkungan yang sehat merupakan harapan/dambaan bagi setiap orang hingga saat ini. Hal tersebut akan sulit untuk diwujudkan karena masih banyak warga masyarakat yang masih kurang peduli dan tidak bertanggung jawab terhadap lingkungan sekitarnya. Pada hakikatnya kepedulian itu sangat memerlukan sebuah proses perjalanan yang sangat panjang karena menyangkut sikap hidup, komitmen kuat, kerjasama yang solid dan bukan sekedar selogan semata. Kita dapat melihat dari sisi alam dan lingkungan hidup yang telah rusak oleh tangan-tangan manusia yang tidak bertanggung jawab. Pengertian lingkungan hidup dalam Pasal 1 angka 1 Undang-Undang Nomor 32 Tahun 2009 tentang pengelolaan Lingkungan Hidup adalah kesatuan ruang dengan semua benda, daya, keadaan dan makhluk hidup termasuk manusia dan perilakunya yang mempengaruhi alam itu sendiri, kelangsungan perikehidupan dan kesejahteraan umum serta makhluk hidup lain.

Masih banyak terlihat di antaranya air tercemar, udara kotor, banjir dan longsor terjadi di setiap daerah di Indonesia. Secara aturan, pencegahan pencemaran dan kerusakan lingkungan hidup sudah diatur dalam Pasal 14 UndangUndang Nomor 32 Tahun 2009 tentang Perlindungan dan Pengolaan Lingkungan Hidup. Dalam perspektif kerusakan terhadap alam dan lingkungan tersebut, diharapkan masyarakat perlu menanam pohon terutama di daerah yang rawan longsor. Penanaman pohon ini sangat penting dilakukan sebagai salah satu upaya dalam perbaikan lingkungan.

Dalam melakukan reposisi lingkungan tersebut, maka pertama-tama diperlukan adanya pemahaman kembali oleh seluruh warga masyarakat mengenai sangat pentingnya menjaga, memelihara lingkungan yang bersih, sehat dan hijau yang meningkatkan derajat kesehatan masyarakat. Berangkat dari itu diharapkan akan muncul suatu kesadaran kolektif sekaligus sebagai tindakan kolektif dalam membenahi dan mempertahankan lingkungan yang sudah tertata dengan baik. Sehingga dengan tingkat kesadaran tersebut, perlu dipahami bahwa lingkungan yang sehat, bersih dan hijau merupakan aset komunitas yang potensial dan merupakan sebuah katalis yang ideal. Hal ini dapat mengintegrasikan antara lingkungan dan masyarakat, dengan mempromosikan sebuah pendekatan ekologis terhadap kesehatan dan kesejahteraan manusia yang didasari pada kontak dengan alam. Untuk tujuan tersebut maka pengabdian masyarakat ini Kami beri judul "Penataan Lingkungan Dengan Penanaman Pohon Untuk Mencegah Terjadinya Longsor Di Desa Urug, Sukajaya, Bogor"

\subsection{Tinjauan Pustaka}

\section{A. Penataan Lingkungan}

Permukiman merupakan sebuah Kawasan lingkungan tempat tinggal manusia. Kawasan tersebut merupakan bagian dari lingkungan alam. Kawasan permukiman merupakan bagian dari lingkungan hidup yang baik 
berupa kawasan perkotaan dan perdesaan. Pemukiman juga berfungsi sebagai lingkungan tempat tinggal dan hunian untuk melakukan kegiatan dalam mendukung kehidupannya (Sadana, 2014 dan Gobel, 2019). Penataan lingkungan merupakan suatu rangkaian kegiatan dalam menata kawasan tertentu, agar bermanfaat secara optimal berdasarkan ketentuan dalam rencana tata ruang wilayah. Sebuah kawasan tertentu juga akan terlihat sebagai sebuah kawasan yang bisa dikatakan baik, apabila kondisi lingkungannya ditata dan dipelihara dengan baik juga. Hal tersebut sesuai dengan peran dan fungsinya dan juga sesuai dengan peruntukan kawasan tersebut. Misalnya lingkungan di sekolah jika tertata rapih, asri, bersih dan tertib, maka dapat melahirkan suasana seperti sekolah pada umumnya.

Aspek dasar yang dapat mendukung konsep penataan lingkungan hidup antara lain sebagai berikut:

1). Keindahan

2). Kenyaman

3). Kerindangan

4). Kebersihan

Hal-hal yang membuat kondisi penataan lingkungan mengalami kerusakan :

1). Proses perencanaan tata ruang belum aspiratif dan akomodatif serta kurang melibatkan peran aktif seluruh pelaku pembangunan atau stakeholder.

2). Masih lemahnya mekanisme dan control terhadap pengendalian (Check and balance) pemanfaatan tata ruang.

3). Kurangnya sosialisasi mengenai tata kota/tata ruang/tata lingkungan kepada masyarakat.

4). Kurangnya kesadaran masyarakat dalam menjaga/memelihara lingkungan sekitar.

5). Efek pemanasan global sebagai dampak yang ditimbulkan oleh berbagai kegiatan pembangunan yang tidak ramah lingkungan.

6). Perubahan fungsi dan tatanan lingkungan; penurunan daya dukung lingkungan; penurunan mutu lingkungan; pengurasan dan penyusutan keanekaragaman fauna dan flora; adanya ketidakterpaduan pengelolaan sumberdaya manusia, sumberdaya alam dan sumber daya buatan dalam pengelolaan lingkungan hidup; kurang optimalnya pemanfaatan ruang wilayah; perusakan dan pencemaran lingkungan; rendahnya peran serta masyarakat; kurang lengkap dan kurang konsistennya sistem informasi lingkungan; belum terintegrasinya ekonomi lingkungan dalam perhitungan investasi pembangunan; belum berkembangnya ilmu pengetahuan dan teknologi pengelolaan lingkungan; lemahnya penegakan hukum untuk pengelolaan lingkungan.

\section{B. Tanah Longsor}

Dalam periode tahun ketahun, bencana tanah longsor atau sering disebut gerakan tanah semakin sering terjadi di Indonesia. Aktifitas tanah longsor merupakan salah satu kejadian alam yang terjadi di wilayah pegunungan, terutama di musim hujan. Bencana longsor beberapa kali terjadi 
melanda Indonesia dalam periode musim penghujan setiap tahunnya (Naryanto et. Al., 2019). Beberapa kejadian yang menimpa wilayah Provinsi Jawa Barat dan khususnya didaerah Kabupaten Bogor. Salah satu lokasinya ada di Desa Urug Kecamatan Sukajaya Kabupaten Bogor. Penyebab utama bencana longsor tersebut dikarenakan curah hujan yang tinggi, sedangkan tanah tidak sanggup menampung air hujan tersebut. Biasanya air hujan tersebut disimpan oleh akar pepohonan yang ada dudaerah perbukitan diatas hulu sungai. Dengan kondisi penebangan liar dikawasan hutan disepanjang sungai dan perbukitan, maka tanah lereng di wilayah perbukitan tergerus air dan tidak ada akar pohon yang mengikatnya dan mengakibatkan bencana longsor. Dari kejadian tersebut perlu dilakukan identifikasi beberapa penyebab lainnya yang berdampak kepada longsor tersebut. Dari hasil identifikasi dengan mengambil informasi dari beberapa kalangan masyarakat sekitar lokasi maupun dari korban bencana longsor sendiri, dapat diambil kesimpulan bahwa bencana longsosrbmemang terjadi akibat penebangan hutan secara liar. Hal lain yang terjadi juga adalah kekurangan atau tidak adanya proteksi lereng diatas bangunan rumah dan dibawah rumah, sehingga erosi tanah terjadi pada setiap musim hujan tiba. Dalam hal penggulangannya dari Pemerintah sedang dibuatkan Rumah Khusus (Rusus) untuk korban benca longsor tersebut bertepatan di depan Kantor Desa Urug seluas \pm 8 hektar.

\section{Konservasi Tanah}

Di wilayah Indonesia, sangat pentingnya konservasi tanah dan air pada satuan sistem Daerah Aliran Sungai (DAS) yang mulai disadari setelah terjadi banjir besar Bengawan Solo pada tahun 1966. Kesadaran atas dampak kejadian tersebut ditindak lanjuti dengan upaya penanggulangan pada skala luas melalui Proyek Penghijauan Departemen Pertanian 001 pada tahun 1969. Sistem pengelolaan DAS untuk mendukung pelaksanaan konservasi tanah tersebut, diformulasikan pada tahun 1972 melalui Proyek Upper Solo Watershed Management and Upland Development Project (TA INS/72/006). Dari perjalanan waktu penyelenggaran dalam pengelolaan DAS, setiap kegiatan pengelolaan DAS dapat diartikan sebagai pengelolaan sumber daya alam (SDA) berskala DAS berdasarkan integrase keterlibatan masyarakat, pengetahuan teknis dan struktur organisasi beserta arah kebijakkan dari kegiatan tersebut. Pendekatan dalam pengelolaan DAS menjadi relevan kembali setelah munculnya beberapa persoalan pengelolaan SDA serta dampak pengelolaan yang buruk. Sementara itu, pendekatan dalam pengelolaan DAS juga mengalami perubahan seiring dengan adanya perubahan situasi, permasalahan, kondisi dan pergeseran paradigma. Ini menguraikan cakupan, permasalahan pengelolaan SDA dan upaya yang perlu dilakukan agar semua pihak dapat mengacunya. Permasalahan DAS ini dapat dilakukan dengan cara melaksanakan penghijauan, yang dilakukan untuk mengurangi erosi tebing sungai yang disebabkan oleh adanya gerusan aliran sungai yang terjadi pada saat hujan lebat dan secara tiba-tiba. Kejadian tersebut ditambah lagi dengan rusaknya hutan dan DAS di bahagian hulu. Adapun yang dikaji dalam artikel ini adalah hal-hal yang berkaitan dengan 
terjadinya kerusakan DAS, penurunan kwalitas air, penurunan muka air suatu waduk dan danau, terjadinya bencana alam (longsor, banjir dan kekeringan), sistem ekologi dan manajemen DAS, peran Agroforestry dalam menanggulangi banjir dan longsor DAS serta Teknologi pengelolaan DAS.

\section{METODE PELAKSANAAN}

\subsection{Kerangka Pemecahan Masalah}

Berikut kerangka pikir dalam pemecahan masalah dengan "Penataan Lingkungan dengan Penanaman Pohon untuk mencegah terjadinya Longsor di Desa Urug, Kecamatan Sukajaya, Kabupaten Bogor ". Untuk lebih jelasnya dapat dilihat dalam skema di bawah ini:

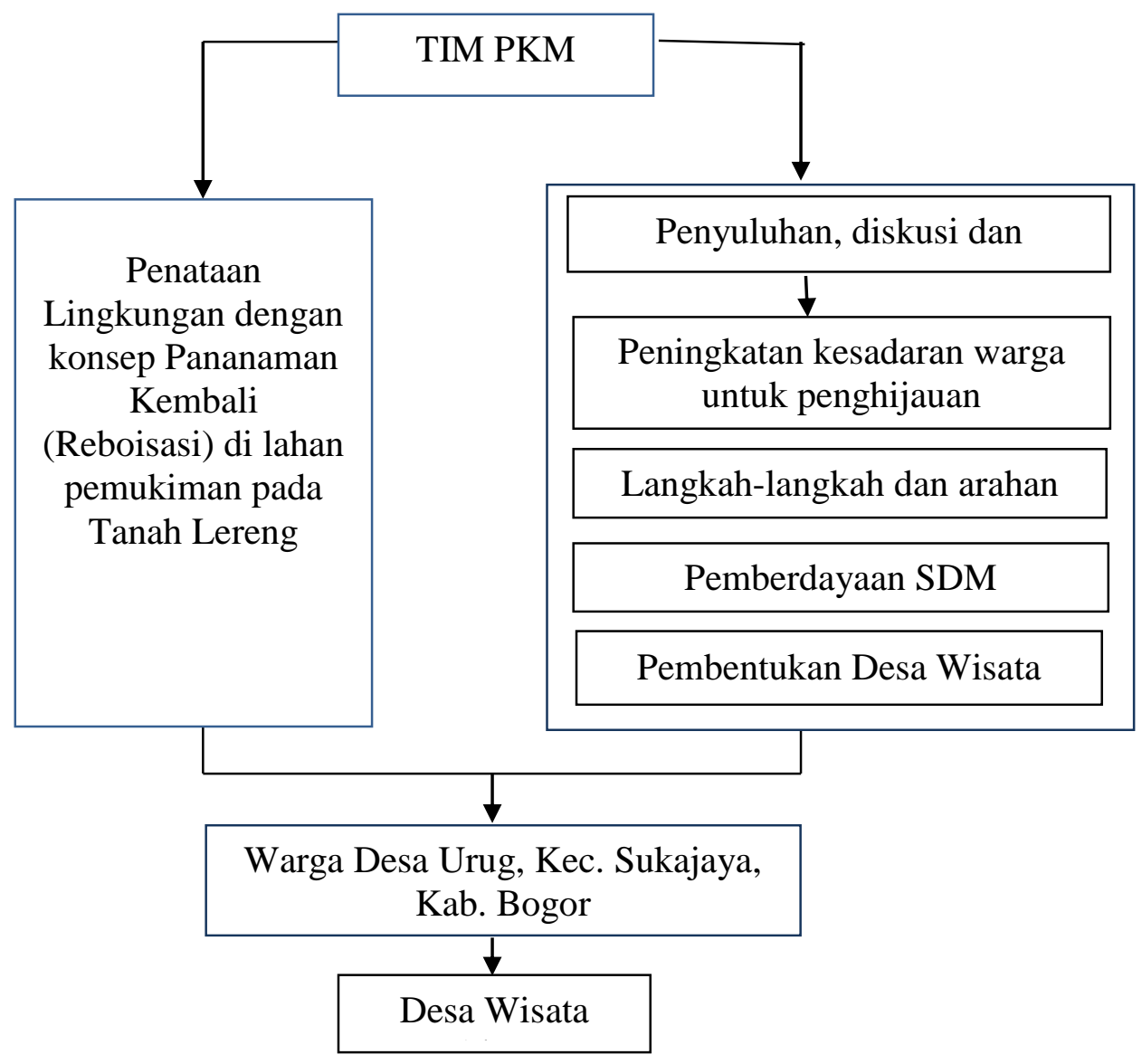

Gambar 1 Skema PKM

\subsection{Metode Pelaksanaan}

Dalam menjalankan program ini, ada beberapa metode pelaksanaan teknis yang dilakukan, diantaranya sebagai berikut: 
1). Menjalin kerja sama dengan Kepala Desa dan perangkat Kantor Desa Urug, Kec. Sukajaya, Kab Bogor.

2). Melakukan sosialisasi melalui penyuluhan dalam penataan lingkungan dan bagaimana melakukan penanaman Kembali (rebosisasi) disekitar lereng yang rawan akan longsor tersebut.

3). Penyerahan bibit pohon untuk ditanamkan dan diberikan contoh dalam penanamannya serta merawat agar tanaman pohon tersebut tumbuh subur.

4). Memberikan pengetahuan cara merawat tanaman yang ditanamkan dan bagaimana cara pemeliharaannya.

5). Memberikan akses kepada masyarakat dan perangkat Desa agar bisa langsung menghubungi bagian pembibitan tanaman hortikultura di Institut Pertanian Bogor.

6). Memberikan pengetahuan agar kelestarian lingkungan akan menjadi sebuat asset dalam pengembangan pariwisata dalam konsep Desa Wisata.

\section{HASIL DAN PEMBAHASAN}

Berdasarkan hasil analisis dan laporan kunjungan yang dilakukan secara teratur setelah pelaksanaan pengabdian masyarakat, dapat dilihat masih terawatnya bibit tanaman yang telah ditaman tersebut dalam usia 2 minggu. Dalam melihat pertumbuhan bibit pohon tersebut akan dilakukan pemantauan berkala, agar semua aktifitas pertumbuhan bibit pohon tersebut dapat dilihat apakah tumbuh dengan subur atau tidak. Variabel pertumbuhan yang diamati yaitu tinggi, diameter dan jumlah daun tanaman. Proses pemantauan tersebut mengacu pada tinggi tanaman yang diukur $1 \mathrm{~cm}$ dari permukaan tanah sampai ke ujung titik pertumbuhan batang. Diameter batang diukur dengan menggunakan caliper dalam satuan mm. pengukuran diameter diukur pada titik $\mathrm{qcm}$ dari permukaan tanah. Jumlah daun yang dihitung adalah berdasarkan pertambahan jumlah daun majemuk yang muncul pada setiap pengamatan. Jumlah daun akan majemuk yang muncul setiap pengamatan. Jumlah daun akan dihitung apabila tangkai daun sudah mulai terlihat jelas, meskipun anak dari daunnya belum membuka secara sempurna (Sukarman et.al.. 2012).

Untuk program Desa Wisata yang diinisasi, akan dilakukan pembahasan selanjutnya setelah rumah-rumah yang dibangun sudah ditempati oleh masyarakat korban longsor. Nantinya akan dibuatkan semacam landscape yang mengatur tanaman apa saja yang layak ditanam, mengingat karakeristik tanaman yang berbeda-beda dan luas pekarangan yang terbatas. Diharapkan program Desa Wisata ini akan terwujud dengan konsep perumahan hijau yang diantara rumahnya terdapat sebanyak 24 unit rumah adat dengan tampilan budaya arsitektural setempat. 
Penataan Lingkungan Dengan Penanaman Pohon Untuk Mencegah Terjadinya Longsor Di Desa Urug, Sukajaya, Bogor
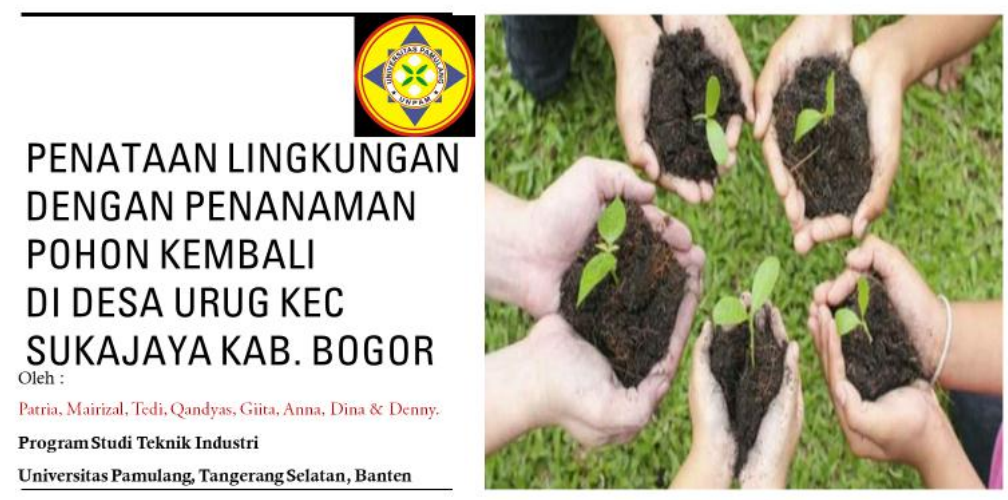

Gambar 2 Halaman muka Materi Pelaksanaan Pengabdian Masyarakat

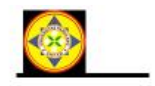

\section{DAMPAK \\ KERUSAKAN LINGKUNGAN}

Bentuk kerusakan lingkungan yang ditimbulkan oleh manusia diantaranya adalah terjadinya tanah longsor, sebagai dampak langsung dari

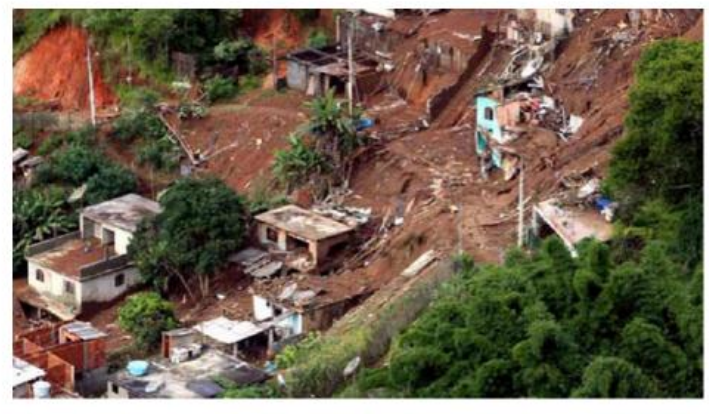
rusaknya hutan.

Gambar 3 Bagian dari Materi Pelaksanaan Pengabdian Masyarakat

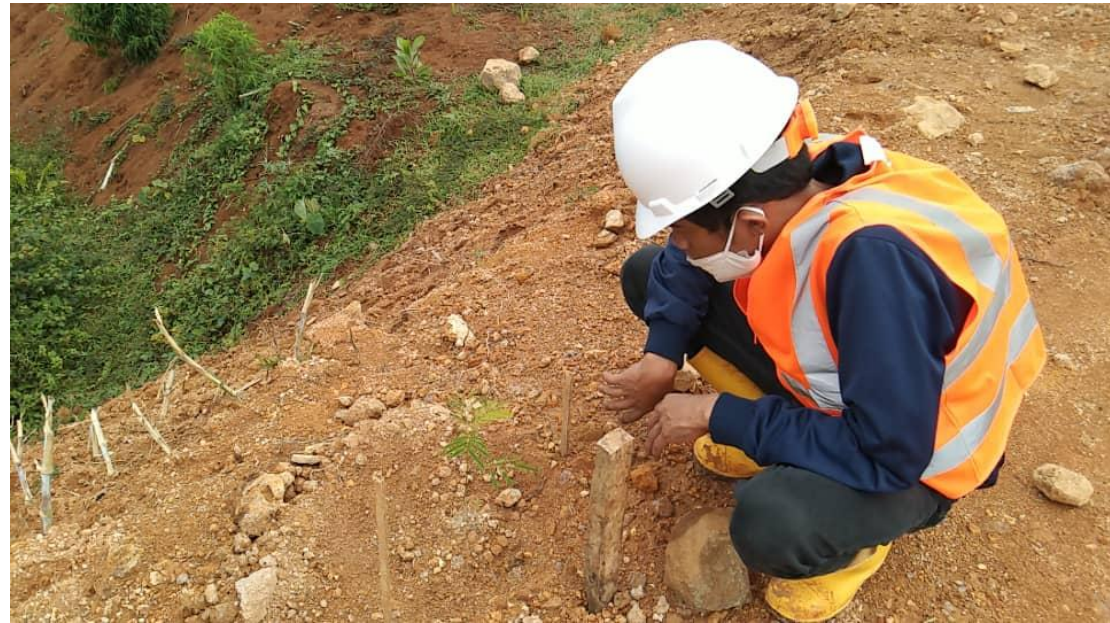

Gambar 4 Bagian dari bibit pohon yang ditanam dekat lereng pemukiman 


\section{SIMPULAN}

Berdasarkan hasil pelaksanaan kegiatan pengabdian tersebut kepada masyarakat yang diselenggarakan oleh Lembaga Penelitian dan Pengabdian Masyarakat (LPPM) dan Dosen Program Studi Teknik Industri Universitas Pamulang adalah sebagai berikut:

1). Melakukan penyuluhan untuk melakukan penataan lingkungan yang ditumbuhi pohon-pohon hortikultura dengan menggunakan konsep penanaman kembali (reboisasi).

2). Entusias masyarakat dengan program ini sangat menunjang program penghijauan pemukiman yang akan menjadi Desa Wisata.

3). Setelah melakukan Pengabdian Masyarakat diketahui bahwa faktor penyebab longsor yang terjadi adalah karena lereng pemukiman tidak didukung oleh akarakar pohon yang kuat dan dalam.

4). Membutuhkan penyuluhan berkala agar terwujudnya konsep Desa Wisata dengan pemukiman yang hijau dan asri.

Berdasarkan hasil kesimpulan didapatkan beberapa saran sebagai berikut:

1). Untuk meningkatkan jumlah pohon yang ditanam, akan dilakukan pengambilan tambahan bibit pohon ke Bagian Penyemaian Bibit Tanaman Hortikultura di Institut Pertanian Bogor.

2). Diperlukan pemanatauan berkala dalam pengembangan Desa Wisata serta melihat pertumbuhan bibit pohon yang ditanam.

\section{DAFTAR PUSTAKA}

Fendy Faizal Gobel. (2019). Konsep Penataan Kawasan Permukiman Desa Lemito. Journal of Infrastructure \& Science Engneering, Gorontalo, Vol. 2 Nomor 2; pp. 31-45

Heru Sri Naryanto, Hasmana Soewandita, Deliyanti Ganesha, Firman Prawiradisastra, dan Agus Kristijono. (2019). Analisis Penyebab Kejadian dan Evaluasi Bencana Tanah Longsor di Desa Banaran, Kecamatan Pulung, Kabupaten Ponorogo, Provinsi Jawa Timur Tanggal 1 April 2017. Jurnal Ilmu Lingkungan, Vol. 1, Issue 2; pp.272-282

Presiden RI. (2009). Undang-Undang Republik Indonesia Nomor 32 tahun 2009 Tentang Perlindungan Dan Pengelolaan Lingkungan Hidup

Sadana, A. S. (2014). Perencanaan Kawasan Permukiman. Yogyakarta: Graha Ilmu

Sukarman, R. Kainde, J.Rombang, dan A.Thomas. (2012). Pertumbuhan Bibit Sangon (Paraserianthes falcataria) pada berbagai media tumbuh. Eugenia, Vol. 18 Nomor 2; pp. 215-220 